\title{
Recent patent applications related to drug discovery automation
}

\begin{tabular}{|c|c|}
\hline Patent number & Description \\
\hline $\begin{array}{l}\text { US } 20110297546 \text {, } \\
\text { EP } 2407777\end{array}$ & $\begin{array}{l}\text { Isotachophoresis method for concentrating and isolating } \\
\text { charged analytes contained in a sample, where each analyte } \\
\text { has an effective electrophoretic mobility. The method involves } \\
\text { applying an axial electric field along the longitudinal axis of a } \\
\text { separation channel, causing a concentration and separation } \\
\text { of the analytes and spacers forming respective focused } \\
\text { spacer zones and focused analyte zones that flow along the } \\
\text { longitudinal axis; followed by spatial displacement of analytes } \\
\text { by selective extraction into extraction channels. }\end{array}$ \\
\hline
\end{tabular}

\section{US 20120010105 A screening system comprising a measurement chamber, automated instruments for microplates and a plate handling system for moving microplates into and out of a screening system; useful for performing label-free assays.}

WO 2011131747

US 20110215798

WO 2011061548

2011075573
US 20110206262 A method for identifying the viscoelastic phase transition of,

A method of high-throughput screening for agents capable of affecting the activity of a G protein-coupled receptor (GPCR) involving exposing a sample of cells to a candidate agent; conducting measurements of light emitted from the sample in an automated manner, where the cells express at least a recombinant nucleotide sequence encoding a chimeric protein.

A monitoring system for conducting automated sampling, sample preparation and/or sample analysis in a multi-well plate assay format, comprising sample collection modules fluidically connected to a detection module, and a plate handling sub-system.

A microfluidic device apparatus for analysis of a sample such as a nucleic acid, comprising magnetic particles connected to the sample, microchip, flow channel and source of oil carrier fluid connected to the channel for moving the sample in the flow channel.

WO 2011102804 An electro-fluidic interface of a multi-well plate used in, e.g., analytical research, with a biasing structure positioned to a sealing portion and an electrode for moving the sealing portion to induce change in pressure in the well. e.g., human embryonic stem cells to detect Parkinson's disease, involving comparing models of feature dynamics from test cells with models of feature dynamics derived from reference cells. for a module of pharmaceutical composition, involving evaluating members of the initial population against achievement objectives, where evaluation includes calculation of vector distance.

A box-shaped object stocker comprising a rotation cassette stand that is rotated so that a cassette may come above a box-shaped object placing board. A box-shaped object is piled up and accommodated in the cassette through an opening part which exists on the lower part of the cassette with the boxshaped object placing board to be taken out from the box-shaped thief outlet to the cassette upper part, or accommodated in the cassette.

Lawrence Livermore

National Security

(Livermore, CA, USA)

Agency for Science, Technology and Research (Singapore)

The Charles Stark Draper Laboratory (Cambridge, MA, USA) (Dundee, UK)

IS Technology Japan Inc. (Tsukuba, Japan), Rorze Corp. (Hiroshima, Japan)
Caracci SJ,
Eckelt VHO,

$7 / 20 / 2005$

Frutos AG,

Krol MF,

Moore TC,

Pastel DA, Shedd GM

Gjoni T,

Gouillier A,

Hampe C,

Luetjens R,

Schelshorn D

Clinton CM

4/19/2010

10/20/2011
$12 / 27 / 2007$

9/8/2011

Beer NR

Peng S, Reboud J,

Yobas L

Desai M, Erb TM,

Lowry N,

Mangoubi R, Sammak PJ

Besnard J, Hopkins AL

Munakata M, 